\title{
Preoperative Stating of Pelvic Lymph Nodes in Prostate Cancer Patients via Endorectal Magnetic Resonance Imaging
}

\author{
VAHUDIN ZUGOR ${ }^{1}$, MELANIE VON BRANDENSTEIN ${ }^{1}$, ILGAR AKBAROV ${ }^{1}$, \\ DANIEL PORRES ${ }^{1}$, REINHARD KÜHN $^{2}$ and APOSTOLOS P. LABANARIS ${ }^{3}$ \\ ${ }^{1}$ Department of Urology, University Hospital of Cologne, Cologne, Germany; \\ ${ }^{2}$ Department of Urology, Martha Maria Medical Center, Nuremberg, Germany; \\ ${ }^{3}$ Department of Urology, Interbalkan Medical Center, Thessaloniki, Greece
}

\begin{abstract}
Background/Aim: The aim of this study was to evaluate the diagnostic sensitivity, specificity and accuracy of endorectal magnetic resonance imaging (e-MRI), as a preoperative staging modality in the diagnosis of lymph node metastasis (LNM) in patients with prostate cancer (PCa). Patients and Methods: Retrospectively, we analyzed data from $N=168$ patients who underwent radical prostatectomy (RP) between 2004 and 2013 at two tertiary medical centres. Prior to RP all patients underwent an e-MRI. Inclusion criteria were: PSA levels $>20 \mathrm{ng} / \mathrm{ml}$ or Gleason score $>7$. Examinations were performed on a closed 1.0-T system combined with an endorectal body phased-array coil, imaging results were correlated with histopathology. Results: $10.7 \% \quad(N=18$ patients $)$ had histologically-proven LNM. e-MRI was true-positive in $N=6$ (33.3\%) and false-negative $N=12$ patients (66.6\%). $N=150$ $(89.3 \%)$ patients without LNM e-MRI were true-negative in $96 \%$ and false-positive in 4\%. Sensitivity was 96\%, specificity was $33 \%$, accuracy was $64.5 \%$. Conclusion: eMRI can be considered a useful preoperative staging modality in diagnosis of LNM.
\end{abstract}

The second most common cause of cancer death in Europe and the United States is prostate cancer (PCa). Around 30\% of all newly diagnosed cancers in males are $\mathrm{PCa}$ (1). In general, in the early stage of the disease, radical prostatectomy including pelvic lymphadenectomy to detect metastatic spread to the lymph nodes is the most common therapy, however, it is well known that the presence of lymph node metastasis is a poor prognostic sign (1).

Correspondence to: Professor Dr. med. Vahudin Zugor, University Hospital of Cologne, Department of Urology, Kerpenerstrasse 62, 50937 Cologne, Germany. Tel: +49 22147896087, Fax: +49 22147882375,e-mail: vahudin.zugor@uk-koeln.de,zugor@web.de

Key Words: Prostate cancer, MRI, lymph node metastasis, staging.
The aim of this study was to evaluate the diagnostic sensitivity, specificity, and accuracy of endorectal magnetic resonance imaging (e-MRI) of the prostate as a preoperative staging modality in the diagnosis of lymph node metastasis (LNM) in patients with biopsy-proven PCa.

\section{Patients and Methods}

A retrospective review of $\mathrm{N}=168$ patients with biopsy proven $\mathrm{PCa}$ who subsequently underwent radical prostatectomy (RP) between April 2004 and April 2013 at two tertiary medical centres was conducted. Prior to $\mathrm{RP}$ all patients underwent an e-MRI of the prostate. Inclusion criteria for the study were PSA levels $>20 \mathrm{ng} / \mathrm{ml}$ or Gleason score $>7$. The presence of one or more lymph nodes with a short axis diameter $>1 \mathrm{~cm}$ was considered as LNM. Interpretation of the images was performed by a highly experienced radiologist blinded to patient clinical data. The examinations were performed on a closed 1.0-T system combined with an endorectal body phased-array coil and imaging results were correlated with histopathology. T1-weighted axial-oriented sequences were applied from the prostate base up to the aorta bifurcation. Regional lymph node resection included external iliac, internal iliac and obturator nodes. The clinicopathological parameters of the patients included age, PSA levels, Gleason score, e-MRI findings, histologically proven LNM, amount of lymph nodes dissected, size of lymph nodes dissected, sensitivity, specificity and accuracy.

\section{Results}

The clinicopathological characteristics of patients are listed in Table I. Out of the $168,10,7 \%$ ( $\mathrm{N}=18$ patients) had histologically proven LNM. The e-MRI was true-positive in $\mathrm{N}=6$ out of 18 patients $(33,3 \%)$ and false-negative in $\mathrm{N}=12$ cases $(66,6 \%)$. $\mathrm{N}=150(89.3 \%)$ patients had no LNM. The e-MRI was truenegative in $\mathrm{N}=144$ out of 150 patients $(96 \%)$ and false-positive in $\mathrm{N}=6(4 \%)$. Concluding these results, a sensitivity of $96 \%$, a specificity of $33 \%$ and accuracy of $64.5 \%$ were shown.

\section{Discussion}

The correct staging of the lymph status is critical to plan an optimal therapy for prostate cancer patients. Many studies 
demonstrated the supporting benefit of MRI in prostate cancer diagnostics (2-5). A sensitivity of $92 \%$ can be achieved respectively for the detection of the extracapsular extension of cancer. Thus, MRI seems a good preoperative support for example at the planning of a robot assisted nerve sparing radical prostatectomy (6-9).

An extended pelvic lymphadenectomy (obturator and external iliac lymph nodes, including the internal iliac lymph nodes) is associated with a high rate of lymph node metastasis outside of the fields of standard lymphadenectomy, in cases of clinically localized prostate cancer (10). For the preoperative detection of lymph node metastasis the conventional CT and conventional magnetic resonance imaging (MRI) seem to be equivalent in the current literature (11).

A meta-analysis in 2008 from Hövels et al. showed for both methods a sensitivity of $39 \%$ and $42 \%$ and a specificity of $82 \%$ (12). They showed that CT and MRI examination of patients have an equally poor quality in the detection of lymph node metastasis. Based on this, the patient will not receive the right therapy (12).

As Heesakers reported a few months later, the MR lymphoangiography (MRL) with use of lymph-node-specific MR-contrast agent ferumoxtran-10, had significantly higher sensitivity and negative predictive value than up-to-date multidetector CT for patients with prostate cancer, who had intermediate or high risk of having lymph-node metastases. In such patients, after a negative MRL, the post-test probability of having lymph-node metastases is low enough to omit a pelvic lymph-node dissection (13).

Choline-based PET/CT examinations demonstrated patient- and lymph node-based sensitivity from $41 \%$ to $64 \%$ and specificity from $90 \%$ to $100 \%$. The limitation of cholinebased PET/CT examinations seems to be at the detection of lymphatic metastases $<5 \mathrm{~mm}$ (14-16).

The detection of micro-metastases is very complicated since the MRT is not a suitable method. In case of micro-metastases, high diagnostic experience is of great importance. Conventional MRI and diffusion-weighted MRI (DWI) have similar limitations $(17,18)$. Seyfer et al. showed in 2014 that a superparamagnetic iron oxide contrast agent MRI (USPIOMRI) is able to differentiate inflammatory from malignant lesions (19). High-resolution USPIO-MRI with magnetic nanoparticles allows the detection of small and otherwise undetectable lymph-node metastases in patients with prostate cancer. In normal-sized lymph nodes having a diameter of $5-10 \mathrm{~mm}$, the literature showed sensitivity of $96 \%$ and specificity of $93 \%$ for the detection of LNM. A drastic decrease of these values were shown for lymphatic sizes of $<5 \mathrm{~mm}$ to $41 \%$ and $98 \%$ respectively $(20,21)$.

Thoeny et al. reported a sensitivity of $80 \%$ and specificity of $87 \%$ by the combination of diffusions enhanced MRI and USPIO enhanced MRI at the detection of smaller metastases (22). In a retrospective feasibility study the DWI was
Table I. Patients' clinicopathological parameters.

\begin{tabular}{lc}
\hline Patients & $\mathrm{N}=168$ \\
\hline Age & $56-74$ (median 65.6) \\
PSA levels & $7.9-68.5 \mathrm{ng} / \mathrm{ml}$ (median 23.3) \\
Biopsy Gleason score & $\mathrm{N}=27(26.1 \%)$ \\
6 & $\mathrm{~N}=36(21.4 \%)$ \\
7 & $\mathrm{~N}=72(42.8 \%)$ \\
8 & $\mathrm{~N}=24(14.2 \%)$ \\
9 & $\mathrm{~N}=9(5.5 \%)$ \\
10 & \\
e-MRT findings & $\mathrm{N}=156$ \\
cN1 & $\mathrm{N}=12$ \\
cN1 & \\
Histologically proven LNM & $\mathrm{N}=150(89.3 \%)$ \\
pN0 & $6-33($ median 17.3$)$ \\
Amount & $0.2-1.6 \mathrm{~cm}($ median 0.73$)$ \\
Size & $\mathrm{N}=18(10.7 \%)$ \\
pN1 & $15-40($ median 21.7$)$ \\
Amount & $0.6-2.1 \mathrm{~cm}($ median 1.1$)$ \\
Size & $96 \%$ \\
Sensitivity & $33 \%$ \\
Specificity & $64.5 \%$ \\
Accuracy & \\
\hline
\end{tabular}

evaluated as a potential tool for characterization of pelvic lymph nodes in patients with prostate cancer (23). They showed a sensitivity of $86 \%$ and a specificity of $85 \%$ to distinguish between benign and malignant lymph nodes. A size-based analysis at a cu-toff of $8 \mathrm{~mm}$ was measured (23). Nowadays, only the prostate-specific antigen based screening (PSA level) has led to a downstaging of prostate cancer, due to the over-diagnosis and over-treatment of patients. Clinical nomograms for the prediction of insignificant disease provide more information than any diagnostic test alone; moreover, nomograms that incorporate MRI or MRI/ magnetic resonance spectroscopic imaging findings with clinical and biopsy data have been shown in the studyby Shukla et al. to improve the prediction of insignificant cancer, meaning cancer with low metastatic potential and good prognosis for the patients (24).

\section{Conclusion}

The results of this study exhibited that although e-MRI can be considered a useful preoperative staging modality in the diagnosis of LNM, it has its limitations as seen through its specificity and accuracy. With the imaging methods only a staging accuracy of a PCa patient can be done, nevertheless, the question is, whether a lymphadenectomy improves the prognosis of a PCa patient significantly. Therefore, a largescale multicentrical study should be performed to figure out the benefit of the imaging method and to highlight the benefit of a radical lymph node surgery. 


\section{References}

1 Sanchez-Chapado M, Olmedilla G, Cabeza M, Donat E and Ruiz A: Prevalence of prostate cancer and prostatic intraepithelial neoplasia in Caucasian Mediterranean males: an autopsy study. Prostate 54: 238-247, 2003.

2 Ghai S and Haider MA: Multiparametric-MRI in diagnosis of prostate cancer. Indian J Urol 31: 194-201, 2015.

3 Pepe P, Garufi A, Priolo G D and Pennisi M: Multiparametric MRI/TRUS fusion prostate biopsy: Advantages of a transperineal approach. Anticancer Res 37: 3291-3294, 2017.

4 Scialpi M, Prosperi E, D’Andrea A, Martorana E, Malaspina C, Palumbo B, Orlandi A, Falcone G, Milizia M, Mearini L, Aisa MC, Scialpi P, De Dominicis C, Bianchi G and Sidoni A: Biparametric versus multiparametric MRI with non-endorectal coil at $3 \mathrm{~T}$ in the detection and localization of prostate cancer. Anticancer Res 37: 1263-1271, 2017.

5 Zugor V, Kuhn R, Engelhard K, Poth S, Bernat MM, Porres D and Labanaris AP: The value of endorectal magnetic resonance imaging of the prostate in improving the detection of anterior prostate cancer. Anticancer Res 36: 4279-4283, 2016.

6 Arsov C, Jankowiak F, Hiester A, Rabenalt R, Quentin M, Schimmoller L, Blondin D, Antoch G and Albers P: Prognostic value of a cell-cycle progression score in men with prostate cancer managed with active surveillance after MRI-guided prostate biopsy - a pilot study. Anticancer Res 34: 2459-2466, 2014.

7 Labanaris AP, Engelhard K, Zugor V, Nutzel R and Kuhn R: Prostate cancer detection using an extended prostate biopsy schema in combination with additional targeted cores from suspicious images in conventional and functional endorectal magnetic resonance imaging of the prostate. Prostate Cancer Prostatic Dis 13: 65-70, 2010.

8 Labanaris AP, Zugor V, Takriti S, Smiszek R, Engelhard K, Nutzel $\mathrm{R}$ and Kuhn R: The role of conventional and functional endorectal magnetic resonance imaging in the decision of whether to preserve or resect the neurovascular bundles during radical retropubic prostatectomy. Scand J Urol Nephrol 43: 25-31, 2009.

9 Wang S, Burtt K, Turkbey B, Choyke P and Summers RM: Computer aided-diagnosis of prostate cancer on multiparametric MRI: a technical review of current research. Biomed Res Int 2014: 789561, 2014.

10 Heidenreich A, Varga Z and Von Knobloch R: Extended pelvic lymphadenectomy in patients undergoing radical prostatectomy: high incidence of lymph node metastasis. J Urol 167: 16811686, 2002.

11 Heidenreich A, Aus G, Bolla M, Joniau S, Matveev VB, Schmid HP, Zattoni $\mathrm{F}$ and European Association of Urology: EAU guidelines on prostate cancer. Eur Urol 53: 68-80, 2008.

12 Hovels AM, Heesakkers RA, Adang EM, Jager GJ, Strum S, Hoogeveen YL, Severens J L and Barentsz JO: The diagnostic accuracy of CT and MRI in the staging of pelvic lymph nodes in patients with prostate cancer: a meta-analysis. Clin Radiol 63: 387-395, 2008.

13 Heesakkers RA, Hovels AM, Jager GJ, van den Bosch HC, Witjes JA, Raat HP, Severens JL, Adang EM, van der $\mathrm{Kaa} \mathrm{CH}$, Futterer JJ and Barentsz J: MRI with a lymph-node-specific contrast agent as an alternative to CT scan and lymph-node dissection in patients with prostate cancer: a prospective multicohort study. Lancet Oncol 9: 850-856, 2008.
14 Scattoni V, Picchio M, Suardi N, Messa C, Freschi M, Roscigno M, Da Pozzo L, Bocciardi A, Rigatti P and Fazio F: Detection of lymph-node metastases with integrated $\left[{ }^{11} \mathrm{C}\right]$ choline PET/CT in patients with PSA failure after radical retropubic prostatectomy: results confirmed by open pelvic-retroperitoneal lymphadenectomy. Eur Urol 52: 423-429, 2007.

15 Scher B, Seitz M, Albinger W, Tiling R, Scherr M, Becker HC, Souvatzogluou M, Gildehaus FJ, Wester HJ and Dresel S: Value of $11 \mathrm{C}$-choline PET and PET/CT in patients with suspected prostate cancer. Eur J Nucl Med Mol Imaging 34: 45-53, 2007.

16 Schiavina R, Scattoni V, Castellucci P, Picchio M, Corti B, Briganti A, Franceschelli A, Sanguedolce F, Bertaccini A, Farsad M, Giovacchini G, Fanti S, Grigioni WF, Fazio F, Montorsi F, Rigatti $\mathrm{P}$ and Martorana G: ${ }^{11} \mathrm{C}$-choline positron emission tomography/ computerized tomography for preoperative lymph-node staging in intermediate-risk and high-risk prostate cancer: comparison with clinical staging nomograms. Eur Urol 54: 392-401, 2008.

17 Budiharto T, Joniau S, Lerut E, Van den Bergh L, Mottaghy F, Deroose CM, Oyen R, Ameye F, Bogaerts K, Haustermans K and Van Poppel $\mathrm{H}$ : Prospective evaluation of 11C-choline positron emission tomography/computed tomography and diffusion-weighted magnetic resonance imaging for the nodal staging of prostate cancer with a high risk of lymph node metastases. Eur Urol 60: 125-130, 2011.

18 Haseebuddin M, Dehdashti F, Siegel BA, Liu J, Roth EB, Nepple KG, Siegel CL, Fischer KC, Kibel AS, Andriole GL and Miller TR: 11C-acetate PET/CT before radical prostatectomy: nodal staging and treatment failure prediction. J Nucl Med 54: 699-706, 2013.

19 Seyfer P: Cancer and inflammation: differentiation by USPIOenhanced MR imaging. Rofo 186: 1140-1148, 2014.

20 Harisinghani MG, Barentsz J, Hahn PF, Deserno WM, Tabatabaei $\mathrm{S}$, van de $\mathrm{Kaa} \mathrm{CH}$, de la Rosette $\mathrm{J}$ and Weissleder R: Noninvasive detection of clinically occult lymph-node metastases in prostate cancer. N Engl J Med 348: 2491-2499, 2003.

21 Seitz M, Bader M, Strittmatter F, Gratzke C, Tilki D, Roosen A, Schlenker B, Reich O and Stief C: Diagnostic work-up for lymph node metastases of urological tumors. Urologe A 49: 356-363, 2010.

22 Thoeny HC, Triantafyllou M, Birkhaeuser FD, Froehlich JM, Tshering DW, Binser T, Fleischmann A, Vermathen P and Studer UE: Combined ultrasmall superparamagnetic particles of iron oxide-enhanced and diffusion-weighted magnetic resonance imaging reliably detect pelvic lymph node metastases in normalsized nodes of bladder and prostate cancer patients. Eur Urol 55: 761-769, 2009.

23 Eiber M, Beer AJ, Holzapfel K, Tauber R, Ganter C, Weirich G, Krause BJ, Rummeny E J and Gaa J: Preliminary results for characterization of pelvic lymph nodes in patients with prostate cancer by diffusion-weighted MR-imaging. Invest Radiol 45: 1523, 2010.

24 Shukla-Dave A, Hricak H and Scardino PT: Imaging low-risk prostate cancer. Curr Opin Urol 18: 78-86, 2008. 